\title{
El discurso de Príamo en la llíada: la referencia
}

\author{
LUCIA ADRIANA LIÑARES \\ Universidad de Buenos Aires - COMICET
}

\begin{abstract}
RESUMO: O estilo valorativo dos parlamentos de Priamo na Illada, que destaca a referência e as suas características, define o conjunto de possíveis valores que constituem o sistema referencial do ancião. Este sistema organiza-se em três categorias: pessoal, temporal e espacial. O presente trabalho interessa-se pelo marco referencial de tempo: os fatos denotados projetam-se num plano não constitutivo da realidade; através da utilização de expressões com formas verbais em subjuntivo e optativo, Priamo revela as "disposições subjetivas" de seus discursos.
\end{abstract}

PALAVRAS-CHAVE: Discurso, referência, valor, anciãos, Illada, pessoa, espaço, tempo.

El presente trabajo forma parte de un proyecto de investigación más amplio ${ }^{1}$, que analiza los parlamentos de los ancianos Néstor, Fénix y Príamo en la Ilíada: dicha investigación, desarrollada metodológicamente en forma interdisciplinaria a partir de técnicas de análisis del discurso ${ }^{3}$, interpreta a la epopeya homérica como una obra literaria en la que los personajes se caracterizan por explicitar, a través de sus intervenciones, una personalidad "diferenciada", en el marco de un "repertorio tradicional" ${ }^{4}$.

El punto de partida para el desarrollo del trabajo subraya principalmente el concepto de interpretación: en esta investigación se define en relación con dos mecanismos de orden semántico ${ }^{5}$ : por un lado, la "asignación de referentes a ciertas expresiones"6; por otro lado (y en virtud de constricciones pragmáticas ${ }^{7}$ ), la interpretación se ha de dar en relación con las actitudes proposicionales que reproduce el discurso de Príamo. La reconstrucción de los mecanismos referenciales y significativos utilizados por el anciano, así como su universo extra-lingüístico, y sus estructuras mentales de acción, se realiza exclusivamente a partir de la observación de los datos que proporciona la Ilíada (constituida como unica fuente de interpretación).

El propósito de este análise consiste en demonstrar que los datos referenciales que proporcionan los discursos de Príamo en la Illada explicitan sus estructuras mentales subyacentes. Focalizando el interés en el marco de referencia temporal, se a de verificar que los hechos denotados se proyectan en un plano no 
constitutivo de la realidad: a través del uso de expresiones verbales en subjuntivo y optativo, se jerarquizarán las "disposiciones subjetivas" subyacentes de sus discursos.

Príamo se presenta con un discurso cuya característica radica en mostrarlo diferente e individual. Como "hablante diferenciado", el viejo no sólo da "información específica sobre objetivos específicos del mundo extralingüístico"8 ${ }^{10}$, sino que además identifica dichos objetos en relación con "ciertos 'puntos de referencia', dentro de un cierto 'sistema de localización'" (Kerbrat-Orecchioni, p.72). Vale decir que, a través de su discurso, Príamo significa y también se refiere a (Kerbrat -Orecchioni, p.72)

El conjunto de objetos individuales conforma un DOMINIO que se constituye en un conjunto de posibles VALORES: las expresiones individuales se interpretan como (denotan, se refieren a) COSAS u OBJETOS INDIVIDUALES como $V A$ LORES (Van Dijk, p.58). En la presente investigación, se define la REFERENCLA como el "proceso de relacionar el enunciado ${ }^{9}$ con el referente, es decir al conjunto de los mecanismos que permiten que se correspondan ciertas unidades lingüísticas con ciertos elementos de la realidad extralingüística" ${ }^{10}$. La particular relación con el mundo ${ }^{11}$ que establece Príamo por medio de la referencia determina el ESTILO VALORATIVO característico de su discurso: las expresiones denotan una serie de objetos como VALORES de un mundo posible. El estilo VALORATIVO da cuenta del DOMINIO (conjunto de posibles valores) del discurso de Príamo. El sistema referencial se organiza en tres categorías: personal, temporal y espacial. Las unidades analizadas proporcionan información sobre individuos/hechos, y también sobre su ubicación en una situación espacio-temporal determinada ${ }^{12}$.

El sistema mental supuesto del personaje-hablante Príamo se reconstruye en cinco subsistemas interrelacionados: conocimientos, creencias, deseos y necesidades (preferencias), intenciones y propósitos y capacidades y habilidades ${ }^{13}$.

1) Un conjunto de conocimientos o CONJUNTO EPISTEMICO "consta de proposiciones ${ }^{14}$ que son 'verdaderas', en el sentido convencional del término, esto es, estas proposiciones están 'garantizadas' por criterios de verdad convencionalmente aceptados (percepción, inferencia correta, informacion de fuentes fehacientes)" (Van Dijk, p.256).

2) Las CREENCIAS (como conjunto) "son proposiciones que no tienen por qué ser verdaderas, pero que el agente piensa que son verdaderas o que probablemente lo son" (Van Dijk, p.256). El conocimiento y las creencias "proporcionan la base de datos para el agente acerca del mundo como es, o como podría ser o llegar a ser" (Van Dijk, p.257).

3) Los DESEOS y NECESIDADES "proporcionan la motivación real" de la acción, "porque se refieren a la estructura del mundo como deberia ser" (Van Dijk, p.257). La diferencia entre deseos y necessidades radica en que los primeros pueden ser irrealizables (Van Dijk, p.257). La preferencia (un estado -o sucesomás deseable que otro) "se basa directamente en los deseos" (Van Dijk. p.257).

4) Si el locutor desea "realizar una necesidad", la transforma en un "PRO. POSITO DE ACCION" (Van Dijk, p.258): "Dado un cierto propósito y el resultado del proceso de hacer una decisión que se traza posibles transcursos de acción, el agente debe formar una INTENCION particular de acción o PLAN de acción, que se ejecute en una situación específica (tiempo, lugar, condiciones)" (Van Dijk, p.258).

5) "El conjunto de $H A B I L I D A D E S$ es estrictamente dependiente del tiempo. Contiene los actos (o más bien conceptos) que podríamos llevar a cabo en un 
momento dado, dadas las condiciones adecuadas. El conjunto de CAPACIDADES puede considerarse como un conjunto más grande, conteniendo también las acciones que podrian hacerse en principio, dado un entrenamiento adicional" (Van Dijk, p.260); se trata de factores que delimitan los alcances de la acción.

El anciano Príamo entabla relaciones comunicativas con varios interlocutores; respecto de las referencias que identifican a la segunda persona, los índices de alocución son constantes y se evidencian a través de dos categorías sintácticas: el Vocativo y el Imperativo ${ }^{15}$. Los discursos dirigidos a Helena en el libro III (162 - 170, 182 - 190. 192 - 197 y 226 - 227) evidencian una organización sencilla, adequada para la pretención de respuestas; no se trata de parlamentos argumentativos com fines persuasivos para una determinada acción; la relación que establece se adecua a las necesidades dramáticas de la obra: desde la perspectiva del enemigo, introduce el desarrollo de la secuencia bélica. Príamo no participa de secuencias comunicativas con los troyanos, sino que se dirige a elles en su calidad de exhortador ${ }^{16}$. Los requerimientos del anciano procuran acciones concretas (abrir y cerrar puerta, preparar el carro) y pretenden atraer la atención (solicitud de que lo escuchen, de que lo permitan entrar o salir). El anciano establece con $H e ́ c u b a^{17}$ y con el dios Hermes ${ }^{18}$ una relación de comunicación que se interpreta como una interacción (Van Dijk, p.266 sq.): el tópico de conversación (es decir, tener la intención de ir a las tiendas de Aquiles con el propósito de rescatar el cadáver de Héctor) ordena la estructura de la interacción (Van Dijk, p.318). Se relaciona con Zeus (XXIV, 308 - 313) en una plegaria, en la que solicita que lo permita cumprir el deseo de ir a las tiendas enemigas. El discurso dirigido a su hijo Héctor en el libro XXII (38 - 76), y el que dirige a Aquiles en el XXIV (486 - 506) manifestan una organisación más completa, pues se trata de secuencias argumentativas con fines persuasivos ${ }^{19}$.

Las intervenciones de Príamo explicitan sus estructuras mentales subyacentes. En primer lugar, jerarquiza en todos los discursos su mayor capacidad: la de percepción (o inferencia consiguiente) ${ }^{20}$. Este factor condiciona la organización de los enunciados y determina el alcance de sus conocimientos y creencias) en virtud de lo que ve e infiere). Las categorías gramaticales, que se verifican en el uso del Vocativo y el Imperativo, especifican sus disposiciones subjetivas constantes y actúan como índices de alocución necessarios para la expresión de finalidad, que se constituye en la estructura fundamental. A través de ella, el anciano declara sus deseos, intenciones y propósitos, y anticipa en forma asertiva los planteos que ha de utilizar como argumentos frente a Aquiles.

Príamo define la situación de comunicación en el marco del presente enunciativo (si bien las exhortaciones como actos de habla denotan hechos futuros de los interlocutores); se vale del tiempo presente para proporcionar información sobre su sistema de conocimientos y creencias (cf. por ejemplo XXI 531-536 frente a los guardias):

\section{...o gar Achillèus \\ engỳs hode klonéon; nân olo lóigi' ésesthai....}

[532-533]

Estas estructuras mentales se interpretan a partir de expresiones verbales definidas como realizativas (en XXI 533, ofo hace referencial al acto de habla ${ }^{21}$ "ejecutado por la propia expresión de estas oraciones en el contexto adecuado" (Van Dijk, p. 287), y de formas adverbiales o partículas que especifican los 
valores de (verdad de) las aserciones (cf. por ejemplo étoi mén en III 168 y ê rá nú en III 183):

étoi mèn kefalêi kai méizones álloi éasi, kaldn d'houto egon oú po idon ophthalmoîsin, oud'houto gerarón, basilêi gdr andri éoiko.

[III 168-180]

ó mákar Atreide, moiregenés, olbiodaimon, ê rá nú toi pollói dedméate kourei Achaiôn...

[III 182-183]

Uno de los aspectos que define el esquema referencial de sus discursos es la explicitación de su capacidad visual (e inferencia o deducción a partir de las evidencias), la cual se jerarquiza en el tiempo presente como criterio o fundamento para un curso de acción a seguir (cf. por ejemplo III 194 sq.) En el tiempo de la enunciación, Priamo hace manifiesta la estructura de sus discursos en lo que se refiere a capacidades, conocimientos y creencias. Se jerarquiza el uso especial de este tiempo para hacer referencia a lo permanente ${ }^{22}$ en la imagen que proyecta frente a Héctor sobre las figuras de un joven y un anciano muertos (cf. XXII 71 sq.):

... néoi dé te pánt' epéoiken areiktaménoi, dedaigménoi oxéi khalkôi, keîsthai, pánta dè kalá thanónti per, hótti phanéei; all'hóte de polión te káre polión te géneion aidô t' aiskýnosi kýnes ktaménoio gérontos, toato de óiktiston péletai deiloîsi brotoîsin.

En cuanto al pasado, a diferencia de lo que ocurre con otros ancianos como Héctor y Fénix en sus discursos, Príamo no se sumerge en sus recuerdos con el objeto de justificar hechos presentes, sino para fundamentar su capacidad perceptiva constante (cf. el elogio a Agamenón en III 182-190):
ô mákar Atreide, moiregenés, olbiódaimon, ê rá nú toi pollói dedméato koâroi Akhaiôn. éde kaì Phrygien eisélython ampelóessan, éntha iden pleistous Phýrgas anéras aiolopolous, laoùs Otrêos kaì Mygdónos antithéoio, hol ra tot' estratoonto par'okhthas Sangarioio; kai gàr egòn epikouros edn metà toîsin elékhthen ématti tôi hóte t'êlthon Amazónes antiáneirai; all'oad'hoi tósoi êsan hósoi hellkopes Akhaiói.

(III 182-190)

Las referencias enmarcadas en el pasado, que en ningún caso revisten carácter argumentativo, son utilizadas para especificar los datos identificativos de un personajo o hecho descripto (en el discurso dirigido a Aquiles en XXIV 486-506, aunque pareciera que la referencia a la muerte de sus hijos en el pasado - cf. vv. 493-501 - tiene fines argumentativos, .específicamente sirve para jerarquizar la figura de Príamo en primera persona, en oposición a la imagen que ha dado de Peleo, la cual sí se constituye, respecto del interlocutor, en argumento persuasivo): 
...autàr egd panápotmos, epéi tékon hyîas aristous Trolei en ourelei, tôn d'oú tiná phemi leleîphthai. pentékonta moi êsan, hót' élython hyîes Akhaiôn; enneakáideka mén moi iês ek nedúos êsan, toús d'állous moi étikton eni megároisi gynaîkes. tôn mèn pollôn thouros res hypd góunat' élysen; hòs dé moi ốos éen, eiryto dé ásty kaì autóus, tòn sù proien kteînas amynómenon peri pátres, Héktora....

[XXIV 493-501]

El rasgo que diferencia categóricamente los discursos de Priamo en cuanto a su marco referencial de tiempo es la proyección de los hechos denotados en un plano no constitutivo de la realidad - ya sea presente o pasada $-{ }^{23}$ : a través del uso de expresiones con formas verbales en subjuntivo y optativo, Priamo jerarquiza las "disposiciones subjetivas" de sus discursos ${ }^{24}$. El esquema referencial no especifica en realidad un sistema objetivo de tiempo, sino que indica la virtualidad del mismo (en tanto participa de las constricciones subjetivas propias de los modos subjuntivo y optativo). Este esquema de tiempo ordena los actos según construcciones que determina el contenido proposicional de los mismos (Van Dijk, p.287): las peticiones denotan actós futuros de los interlocutores; las finalidades asertivas (que valen como promesas, peticiones y declaración de propósitos) hacen referencia a actos futuros de hablante y oyentes; las evaluaciones asertivas denotan la capacidad de Príamo como observador; las expresiones desiderativas e hipotéticas denotan hechos virtuales (posibles e imposibles) de los protagonistas discursivos. Salvo, entonces, las referencias (presentes) a sus conocimientos-creencias y capacidades, y los datos identificativos localizados en el pasado, los discursos de Priamo organizan en un plano virtual la especificación de cuatro valores: voluntad, eventualidad, deseo y posibilidad.

1) El valor de la voluntad está articulado en la forma de expresiones de finalidad: Príamo explicita sus propositos e intenciones, proyectando su subjetividad más allá de los hechos reales ${ }^{25}$ (cf. por ejemplo VII $369,373,375$, etc. ${ }^{26}$ ):

kéklyté meu, Trôes kaì Dárdanoi ed'epíkouroi, ophr'épo tá me thymos eni stéthessi keleúei....

[VII 368-369]

...eipómen Atreídeis; Agamémnoni kaì Meneláoi,...

[VII 373]

...kaì dè tód'eipémenai pykinòn épos, aí k'ethélosi..

[VII 375]

2) El valor de la eventualidad emparenta al subjuntivo con el tiempo futuro (Humbert, p.151 sq.), en tanto coloca en primer plano la virtualidad de un hecho que ha de realizarse. Lo más destacable, en virtud del mecanismo referencial de los discursos de Príamo, es la definición de eventualidad como fundada "sobre una previsión de la realidad, a partir de observaciones anteriores" (Humbert, p.113): teniendo en cuenta la capacidad característica del anciano a través de sus intervenciones, entonces la expresión de la eventualidade da cuenta de un procedimiento identificativo de sus parlamentos. Se jerarquisan cuatro mecanismos: 
a) a través del uso del futuro en proposiciones independientes, Príamo concreta la expresión de promesas y declaraciones de intención ${ }^{27}$ (cf. XXII 40 28,61 sq., XXIV 219 y 223 sq.):

...all' ei mèn zóousi metà stratôi, ô t'àn épeita khalkôu te khrysôu t' apolysómeth';...

[XXII 49-50]

...pròs d'emè tòn dýstenon éti fronéont' aléeson, dýamoron, hón ra patèr Kronídes epi géraos oudôi aisei en argaléei phthisei, kakà póll' epidónta, hyîas t'ollyménous helketheisas te thýgatras,...

[XXII 59-61]

...autòn d'àn pýmaton me kýnes próteisi thýreisin omestai erýousin, epei ké tis oxéi khalkôi týpsas eè balon rethéon ek thymón héletai, hoùs tréphon en magároisi trapezêas thyraoroús, hoi $k$ ' emòn haîma pióntes alýssontes peri thymôi keisont' en prothýroisi...

[XXII 66-71]

mé $m$ ' ethélont' iénai katerýkane, medé moi auté órnis eni megároisi kakòs péleu; oudé me peiseis....

[XXIV 218-219]

...nûn d'autòs gàr ákousa theôu kaì esédrakon ánten, ê̂mi, kai oukh hálion épos éssetai....

[XXIV 223-224]

b) la explicitación de sus temores y creencias se constituye en mecanismo introdutor de referencias virtuales (cf. XXI 531 sq.):

... nân oío loigi' ésesthai...

[XXI 533]

...deídia gàr mè oûlos anèr es teîkhos háletai.

[XII 536]

c) se jerarquiza el uso de expresiones de tiempo articuladas en proposiciones adverbiales como delimintadoras del alcance de los hechos futuros (cf. por ejemplo, VII $\left.376-378^{29}\right)$ :

...kaì dè tód' eipémenai pykinòn épos, ai k' ethélosi páusasthai polémoio dysekhéos, eis hó ke nekroùs keiomen; hýsteron aûte makhesómeth', eis hó ke daímon ámme diakrínei, dôei d' hetéroisi ge niken.

[VII 375-378]

d) su capacidad perceptiva y la inferencia a partir de las percepciones visuales le permiten construir imágenes enmarcadas en la eventualidad de su preyección (cf. la descripción de su propia muerte frente a Héctor en XXII 60 sq., especialmente 71-76, donde se jerarquiza el rasgo de iteración de la imagen en virtud de su alcance simbólico): 
aidê t' aiskhýnosi kýnes ktaménoio gérontos, touto dè oiktiston péletai deiloîsi brotoîsin.

[XXII 73-76]

e) se incluye en este punto el uso de expresiones condicionales (en algunos casos su apódosis - elidida - se interpreta en el contexto ${ }^{30}$. Como mercadoras de eventualidad incierta (cf."ke" + subjuntivo), se relacionan siempre con el plano futuro, y hacen referencia a una ideia de espera, con matiz de finalidad (Chantraine, v. II, p.282). Cf. VII $375^{31}$ sq.

...ai $k^{\prime}$ ethélosi

paúsasthai polémoio dysekhéos,... [VII 375-376]

3) Se hace referencia a la noción de deseo por medio de diferentes tipos de expresiones. El optativo en este caso expresa la realización posible del deseo, en tanto que el empleo de "ophello" indica la imposibilidad del mismo (Humbert, p. 118) (cf. XXII 41-42, 426, XXIV 226 -explicitado en el realizativo bóulomai-, 253-254 y 246):

...aithe theoîsi philos tossónde génoito.

hósson emoil tákha kén he kýnes kai gýpes édonthai

kéiomenon; $\hat{e}$ ké moi ainòn apd prapidon ákhos élthois;

hós m' hyiôn pollôn te kaì esthlôn eanin étheke,

kteínon kai pernás néson epi teledapáon....

[XXII 41-45]

...hos óphelen thanéein en khersìn emêisi!

tô ke koressámetha kláienté te myroméno te,

méter th', hé min étikte dysámmoros, ed' egò autós.

[XXII 426-428]

...ei dé moi aîsa

tethnámenai parà neysin Akhaìôn khalkokhitónon,

bóulomai; autíka gár me kataktéineien Akhilleùs

ankàs helént' emón hyión, epèn góou ex éron heíen.

[XXIV 224-227]

spéusate moi, kakd tékna, katefónes!; aith' háma pántes

Héktoros ophélet' anti thoêis epì neüsì pephásthai..l

[XXIV 253-254]

...autàr égoge

prin alapazoménen te pólin keraizoménen te

ophthalmoîsin idêin, baien dómon idos eíso.

[244-246]

4) Los tres primeros ejemplos de deseo anteriores (vale decir: XXII 41-42, 426y XXIV 226) se constituyen en antecedentes (condicionales) para interpretar el alcance de las expresiones de posibilidad ${ }^{32}$. Así, a continuación de "aithe..." en XXII 41, siguen dos frases que hacen referencia a circunstancias posibles. En XXII 427-428, expresa con el optativo la (im-) posibilidad en el pasado (Humbert, p.120), luego de haber hecho referencia al deseo (imposible) que sirve de antecedente (cf. el v. 426). La expresión realizativa (cf. XXIV 226: bóulomai...) introduce una posibilidad que la vez es especificada en su alcance por una expresión 
temporal (el optativo de esta proposición se explica por atracción del optativo de la principal (Chantraine, vol. II, p. 260).

Si se interpretan los períodos condicionales de los parlamentos de Priamo, se observa independencia (y no relación fija de condición-consecuencia) entre las proposiciones y las oraciones principales ${ }^{33}$ (cf. por ejemplo, XXIV 660-661, en que la prótasis reposa sobre la realidad, y la apódosis hace referencia a una consecuencia potencial (la construcción participial hôde...moi rézon -661- reformula la prótasis real y la traduce en expresión potencial)):

ei mèn dé m' ethéleis telésai táphon Héktori díoi, hôde ké moi réson, Akhilêu, kekharisména theíes...

[XXIV 660-661]

Las referencias son eminentemente deícticas ${ }^{34}$. En la relación que establece con Helena, sus peticiones cintienen un pedido de especificación de referentes, los cuales son evaluados por el anciano en virtud de los datos que su capacidad visual proporciona. En los parlamentos dirigidos a los troyanos, Príamo ofrece información referencial para poder interpretar las estructuras mentales que subyacen a su discurso. También frente a sus hombres hace referencia a los argumentos que desarrollará frente a Héctor y Aquiles. En la interacción con Hécuba, procura obtener identificación con su sistema de referencias (a partir de lograr acuerdo en intenciones y propósitos). La plegaria a Zeus se constituye en un intento por parte de Príamo de definir el significado del discurso: el aval de la divinidad cunple su deseo. La interacción que establece con Hermes constituye una oportunidad para que evidencie una ves más su capacidad perceptiva. En este caso el referente de sus discursos es el proprio Hermes, quien en princípio es definido en virtud de lo que Príamo ve e infiere; solicita de su interlocutor especificación como referente (desconociendo los datos proporcionados por Iris por parte de Zeus al comienzo del libro XXIV). En los discursos argumentativos (a Héctor y Aquiles), se hace evidente la habilidad para utilizar su capacidad perceptiva en la creación de imágenes, mediante las cuales determina puntos de referencia adecuados. El presente enunciativo proporciona el marco adecuado para que el anciano explicite las "disposiciones subjetivas" clasificadas segun cuatro valores: voluntad, eventualidad, deseo y posibilidad.

La modalidad referencial propia de los discursos de Príamo especifica un dominio diferenciado que define su ESTILO VALORATIVO: tanto los objetos individuales (personas, cosas) como los hechos denotados manifiestan en los discursos de Príamo la aplicación de un juicio de valor cualitativo o cuantitativo ${ }^{35}$ en virtud de la percepción visual de los hechos a los que se hace referencia, y en virtud también de su proyección en un marco de virtualidad "subjetiva".

\section{Notas}

1- Desarrollado desde 1986 durante las becas otorgadas por el Consejo Nacional de Investigaciones Científicas y Técnicas: Iniciación (Organización y funciones del discurso de Néstor en la Ilíada); Perfeccionamiento (Las Modalidades del discurso en la Ilíada: Néstor, Fénix y Príamo), bajo la dirección de la Lic. Elena F. Huber. 
2- Para el presente trabajo, se ha utilizado la siguiente edición: Monro \& Allen $1920^{3}$.

3- Los conceptos se apoyan principalmente en Teun van Dijk (Teun van Dijk, 1984 -orig. 1977-).

4- El artículo de Paul Friedrich \& James Redfield (Friedrich \& Redfield 1978 p. 253-288) se constituye en punto de partida para esta interpretación de los personajes homéricos como hablantes, identificados por "idiolectos" (sin perder de vista el sustrato común que se define como "repertorio tradicional"). Cf. también la polémica a partir de este artículo (Messing, 1981 p. 888-900 y Friedrich \& Redfield, 1981 p. 901-903).

5- Van Dijk define (van Dijk, 1984 -orig. 1977- p. 34) a la semántica como una "teoría que explica tanto el significado como la referencia, y tanto el significado léxico como las condiciones de significación general determinadas por el conocimiento del mundo".

6- Cf. van Dijk (van Dijk, 1984 -orig. 1977- p. 33) para el desarrollo de este punto.

7- El análisis pragmático apunta a describir los actos de habla y la secuencia de actos de habla, en términos de una teoría de la acción (cf. van Dijk, 1984 -orig. 1977, p. 239 sq.).

8- Cf. Kerbrat-Orecchioni (Kerbrat-Orecchioni, 1986, p. 72) para esta definición de la referencia.

9- Enunciado es la materia enunciada, el objeto de la enunciación, que implica un proceso (événement raconté) y uno o los dos protagonistas (el sujeto del enunciado puede coincidir o no con el sujeto de enunciación): esta definición la propone André Meunier (Meunier, 1974, p. 12).

10- Según la propuesta metodológica de Kerbrat-Orecchioni, 1986, p. 46.

11- Cf. Emile Benveniste (Benveniste 1987 - 7ma. ed. vol. II cap. V, p. 82-91), para la ubicación de este aspecto en el desarrollo del planteo.

12- Para los deícticos específicamente, cf. Kerbrat-Orecohioni, 1986, p. 91, y para el desarrollo global del planteo, cf. Kerbrat-Orecchioni, 1986, p. 41 sq.

13- Se sigue el criterio de van Dijk 1984 -orig. 1977- p. 256 sq.

14- Van Dijk 1984 -orig. 1977- p. $72-73$ denomina proposiciones a los conceptos de hechos.

15- Cf. el status lingüístico característico del alocutario en Kebrat-Orecchioni, 1984 , p. 204, sq.

16- III 304-309, VII 368-378, XXI 531-536, XXII 416-428, XXIV 239-246, 253-264, 716-717 y $778-781$.

17- XXIV 194-199, 218-227 y 300-301.

18- XXIV 373-377, 387-388, 406-409 y 425-431.

19- Se ha presentado un trabajo sobre los mecanismos de organisación de los discursos de Príamo, en el XI Simposio Nacional de Estudios Clásicos, Rosario, Santa Fe, Argentina, septiembre de 1990.

20- Esta es la fuente básica de su conocimiento: cf. van Dijk 1984 -orig. 1977-p. 305. En esta investiagación se define a la inferencia simplesmente como deducción a partir de las evidencias. 
21- Van Dijk 1984 -orig. 1977- p. 278 define actos de habla "al decir que HACEMOS algo cuando hacemos una expresión", o sea que "llevamos a cabo algún acto social específico, por ejemplo, hacer una promesa, una petición, dar un consejo, etc...". 22- Cf. la clasificación de los tiempos en Jean Humbert (Humbert 1960 3 , p. 137), para el presente permanente o universal: ...il est propre d exprimer le 'permanent', qui dépend plus encore de l'aspect duratif du thème que du temps proprement dit.

23- Humbert $1960^{3}$, p. 110 define al modo indicativo como el único que expresa "les conditions constitutives de la réalité" (ya presentes, ya pasadas).

24- Cf. Humbert $1960^{3}$, p.113: En opposition avec l'indicatif, qui constate 'objectivement', le subjonctif et l'optatif expriment des dispositions 'subjectives'.

25- Cf. Humbert $1960^{3}$, p. 113-114: Le subjonctif de volonté se présente sous des formes diverses dans les propositions indépendentes ainsi que dans les propositions subordonnés: mais qu'il s'agisse d'exhortation, de prohibition, de déliberation, d'appréhension ou de finalité, on a toujours d faire dune volonté s'appliquant, soit à la personne dont elle émane, soit d une personne (ou un object) extérieure. Se observa que en los discursos de Príamo, la expresión de finalidad sigue inmediatamente después de un imperativo.

26- Cf. también III 163, 166, XXII 39, 56-58, 416-418, XXIV 195-196, 199, 218, $264,312-313,431,502,555,635$ y 716 .

27. John L. Austin (Austin, 1982 -orig. 1962- p. 205-206) considera una clase de verbos, los compromisorios, entre los que incluye también aquellos que declaran intención. "Las declaraciones de intención difieren de los compromisos, y podría cuestionarse si cabe incluirlos en la misma clase (...). Hay también un deslizamiento hacia los 'descriptivos'. En un caso extremo puedo, 'simplesmente', enunciar que tengo una intención, pero también puedo declarar o expresar o anunciar mi intención o determinación".

28- Pierre Chantraine (Chantraine, 1953, vol. II, p. 225 sq.) considera que éste es un pasajo ambiguo: subjuntivo aoristo o futuro + ke/an?

29- Cf. también XXI 531-532, 534-535, XXII 74, XXIV 227, 245-246 y 717.

30- Cf. explicación en Anatole Bailly (Bailly, 1950) para el análisis de "ei".

31- Cf. también XXII 55, 419, XXIV 301 y 667.

32- Para el "status inlocutivo de las oraciones condicionales", cf. van Dijk 1984 -orig. 1977- p. 308 sq.""la prótasis no se refiere al acto de habla, sino a los actos mencionados en la cláusula principal, es decir, como condición suficiente e necesaria para estos actos".

33- Cf. Humbert, $1960^{3}$, p. 219: Le dévéloppement de la subordination en grec n'a pas fait disparaître cette autonomie premiere".

34- Cf. Kerbrat-Orecchioni, 1984, p. 48: Los deĺcticos son "las unidades lingüísticas cuyo funcionamiento semántico-referencial (...) implica tomar en consideración algunos de los elementos constitutivos de la situación de comunicación, a saber: - el papel que desempeñan los actantes del enunciado en el proceso de la enunciación;

- la situación espacio-temporal del locutor, y eventualmente, del alocutario".

35- Cf. Kerbrat-Orecchioni, 1984, p. 113. Príamo jerarquiza en sus discursos principalmente el uso de adjetivos evaluativos no axiologicos (evaluando cualitativa y cuantitativamente las personas denotadas por la expresión a la que determinan): cf. Kerbrat-Orecchioni, 1984, p. 112 sq. 


\section{Referencias Bibliográficas}

AUSTIN, John L., Cómo hacer cosas con palabras. Baracelona: Paidós, 1982 (orig. Oxford, 1962).

BAILLY, Anatole, Dictionnaire Grec-Francais. Paris: Hachette, 1950 (se han consultado otros diccionarios, como por ejemplo el de Liddell-Scott-Jones, pero sólo se cita éste por el modo de organización y planteo del tema citado en nota.

BENVENISTE, Émile, Problemas de lingüística general. México: Siglo XXI, 1987 vol. II (orig. Paris, 1974).

CHANTRAINE, Pierre, Grammaire Homérique II -Syntaxe-. Paris: Klincksieck, 1953.

VAN DIJK, Teun, Texto y contexto. Traducción de Juan Domingo Moyano. Madrid: Cátedra, 1984 (orig. London, 1977).

FRIEDRICH, Paul \& REDFIELD James, Speech as a personality symbol: The case of Achilles. Language: Baltimore, vol. LIV, 2, p. 253-288, 1948.

FRIEDRICH, Paul, Contra Messing. Language: Baltimore, vol. LVII, 4 p. 901-903, 1981.

HUMBERT, Jean, Syntaxe Grecque. Paris: Klincksieck, $1960^{3}$.

KERBRAT-ORECCHIONI, Cathérine, La enunciación. De la subjetividad en el lenguaje. Buenos Aires: Hachette, 1986.

KIRK, Geoffrey S., Los poemas de Homero. Traducción de Eduardo J. Prieto \& Ramón Alcalde. Buenos Aires: Paidós, 1968 (orig. London 1962).

MESSING, Gordon, On weighing Achilles'winged words. Language: Baltimore, vol. LVII, 4, p. 888-900, 1981.

MEUNIER, André, Modalité et communication. Langue française: Paris, vol. XXI, p. 8-25, 1974.

MONRO, David \& ALLEN, Thomas W., Homeri Opera. Oxford: Clarendon Press, $1920^{3}$, vols. I \& II.

LIÑARES, L. A. Le discours de Priam dans l'Iliade: la référence. Classica, São Paulo, 5/6: 57-67, 1992/1993.

RESUMÉ: Le style valoratif des discours de Priam dans l'lliade sert à présentar la référence et ses caractéristiques, et définit l'ensemble de possibles valeurs constitutifs du système référentiel du vieux. Ce système est organisé en trois catégories: de personne, de temps et de lieu. Le présent travail s'intéresse à la référence temporelle: les faits dénotés se projettent sur un plan non constitutif de la réalité; Priam présente les "dispositions subjectives"de son discours à travers des expressions en subjonctif et optatif.

MOTS CLÉS: Discours, référence, valeur, vieillards, lliade, personne, espace, temps. 